\title{
A Economia Solidária no Centro das Discussões: um trabalho bibliométrico de estudos brasileiros
}

\author{
Juliano Nunes Alves \\ Universidade de Cruz Alta / Departamento de Administração, Cruz Alta - RS, Brasil \\ Viviane FLAVIANO \\ Universidade Federal de SANTA Maria / Departamento de AdMinistraçÃo, SANTA MARIA - RS, Brasil \\ LEANDER LUIZ KLEIN \\ Universidade Federal de SANta Maria / Departamento de Administração, SANTA Maria - RS, Brasil \\ MAURI LEODIR LÖBLER \\ Universidade Federal de SANTA Maria / Departamento de AdMinistração, SANTA MARIA - RS, Brasil
}

Breno Augusto Diniz Pereira

Universidade Federal de SANta Maria / Departamento de AdministraçÃo, SANTA MARIA - RS, Brasil

\begin{abstract}
Resumo
O objetivo deste trabalho é identificar e avaliar as publicações sobre o tema Economia Solidária. Com isso, busca-se compreender o estado de evolução do tema por meio de um processo de organização, classificação e análise de um conjunto de informações e dados bibliométricos. A pesquisa sobre Economia Solidária foi estabelecida nas publicações em periódicos da base da SciELO e SPELL. Foram encontrados 93 artigos publicados sobre o tema em 13 anos de análise (2001 a 2013). Com as recomendações contidas nessas agendas, foram analisados os progressos obtidos pela pesquisa, mostrando a evolução das publicações com o aumento ou a diminuição de sua quantidade a cada ano, os principais autores e as redes de relações entre eles. Os critérios de análise empregados foram os títulos e os resumos de todos os artigos publicados. Os artigos avaliados demonstraram que as publicações são oriundas de diferentes grupos de pesquisas sobre o tema, mas, em contraponto, verificou-se a necessidade de periódicos sobre Economia Solidária.
\end{abstract}

Palavras-chave: Economia Solidária. Publicações brasileiras. Evolução dos estudos.

\section{The Solidarity Economy at the heart of the debate: a bibliometric work of Brazilian studies}

\begin{abstract}
The aim of this work is to identify and evaluate publications on the topic economy of solidarity. Thus, we seek to understand the status of the issue through a process of organization, classification and analysis of a set of bibliometric data and information. Research on economy of solidarity was established based on publications in journals of Scielo and Spell. We found 93 articles published on the topic in 13 years of analysis (2001-2013). With the recommendations contained in these agendas, we analyzed the progress made by research showing the evolution of publications with the increase or decrease of their quantity each year, the main authors and the networks of relationships between them. The analysis criteria used were the titles and abstracts of all the published articles. Articles that were evaluated showed that the publications are coming from different groups of research on the topic; however, there is a need for periodicals on economy of solidarity.
\end{abstract}

Keywords: Solidarity Economy. Brazilian publications. Evolution of study.

\section{La economía solidaria en el centro de las discusiones: un trabajo bibliométrico de estudios brasileños}

\section{Resumen}

El objetivo de este estudio es identificar y evaluar las publicaciones en el tema de la Economía Solidaria. Por lo tanto, se busca comprender el estado de evolución del tema por medio de un proceso de organización, clasificación y análisis de un conjunto de informaciones y datos bibliométricos. La búsqueda sobre Economía Solidaria se estableció en las publicaciones en revistas de las bases SciELO y SPELL. Se han encontrado 93 artículos publicados sobre el tema en 13 años de análisis (2001 a 2013). Con las recomendaciones contenidas en estas agendas, se ha analizado el progreso obtenido por la encuesta, mostrando la evolución de las publicaciones a través de lo aumento o disminución de la cantidad de publicaciones a cada año, los principales autores y las redes de relaciones entre ellos. Los criterios de análisis empleados fueron los títulos y resúmenes de todos los artículos publicados. Los artículos revisados mostraron que las publicaciones son de diferentes grupos de investigación sobre el tema, pero, en cambio, se encontró la necesidad de periódicos sobre la Economía Solidaria.

Palabras clave: Economía Solidaria. Publicaciones brasileñas. Evolución de los estudios. 


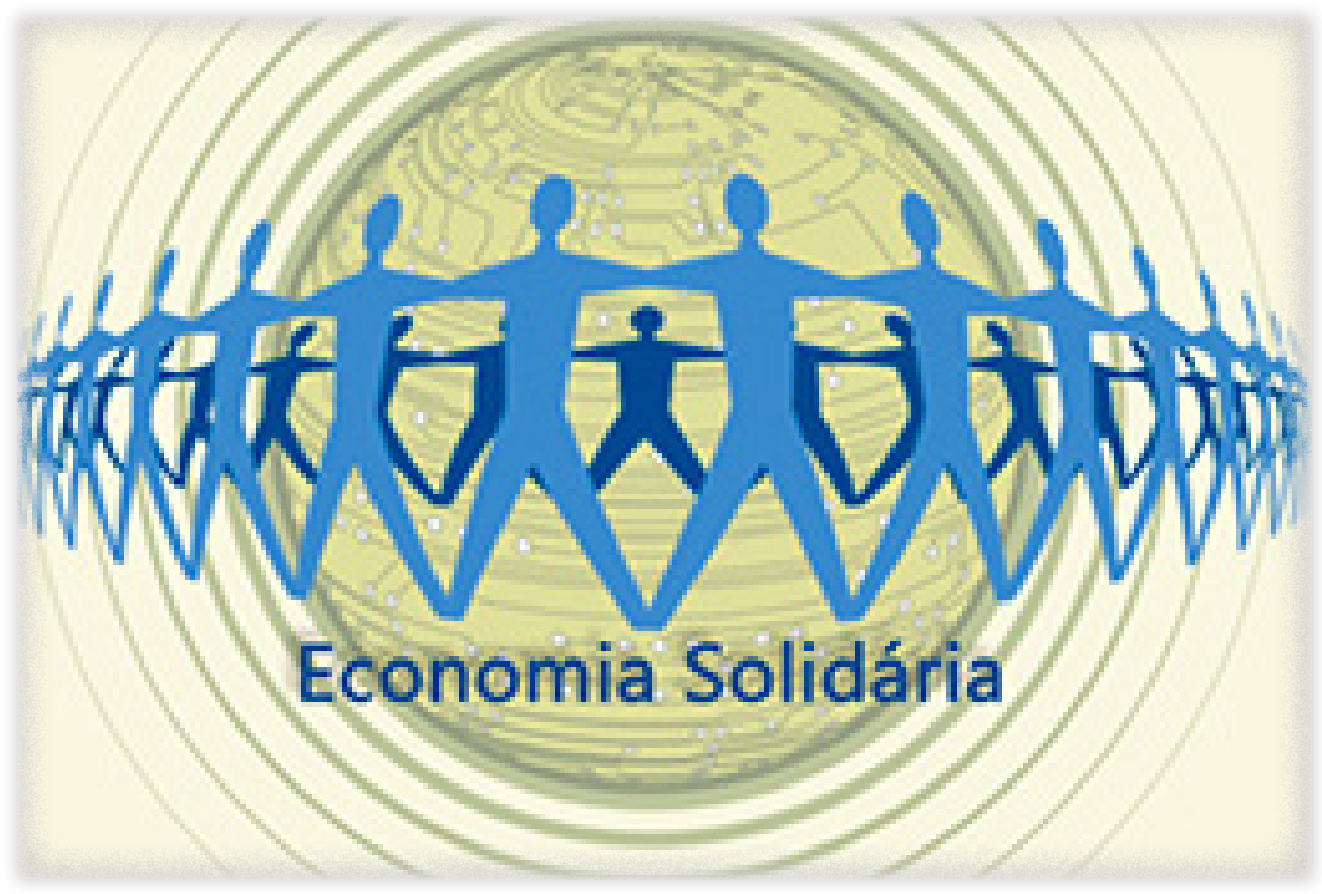

\section{INTRODUÇÃO}

Nos últimos anos, um evento que está se tornando notório no ambiente organizacional no Brasil é a crescente formação de empreendimentos sociais baseados na livre associação. Estes, no entendimento de Gaier (2011), são um fenômeno observado em muitos países há pelo menos uma década e são fundamentados nos princípios da autogestão, cooperação e solidariedade. Para Oliveira, Rezende e Carvalho (2010), a reconfiguração econômica envolvendo a incorporação de obrigações sociais está ocorrendo vagarosamente, mas de forma efetiva. Essas mudanças e princípios redirecionam a realização de novos e diferentes negócios, e encontram-se no âmbito da Economia Solidária, que será tratada nesse trabalho e vem sendo tema de crescente interesse das comunidades acadêmica e empresarial.

Os estudos no campo da Economia Solidária têm alcançado, recentemente, cada vez mais destaque e importância nos negócios (BARRETO e PAULA, 2009). Na concepção de Barretos, Lopes e Paula (2011), a proposta da Economia Solidária emerge como uma possibilidade de geração de renda, inserção e mudança social. Em seus estudos, eles questionaram esse tema de estudo da seguinte maneira: em que consiste o movimento da Economia Solidária? Conceitualmente, a Economia Solidária se baseia na ideia de que os benefícios da atividade econômica devem estar ao alcance daqueles que a realizam, ou seja, dos trabalhadores. Tal proposta diferencia-se da realidade da sociedade centrada no mercado, justamente em função dos seus princípios e valores. Seus fundamentos são o humanismo, a liberdade, a igualdade, a solidariedade e a racionalidade. As primeiras iniciativas se deram em forma de cooperativas em busca de recuperar o trabalho e a autonomia econômica, perdidos em nome da lógica capitalista (SINGER, 2002).

Apesar das diferentes definições que têm sido dadas ao movimento, e que refletem, inclusive, as diferentes perspectivas que coexistem sobre o tema, alguns elementos são considerados fundamentais, como a cooperação, a igualdade e a solidariedade. Independentemente do ponto de vista, é fato que a Economia Solidária constitui um caminho alternativo, capaz de possibilitar aos envolvidos a vivência da imersão de dimensões sociais - e aqui, leia-se laços sociais, solidariedade, ajuda mútua - no

\footnotetext{
* Fonte da imagem: Economia Solidária. Disponível em <http://www.ucibra.com.br/ct-menu-item-8> Acesso em 14 mar. 2016.
} 
campo econômico. Tais iniciativas representam uma possibilidade para os excluídos do mundo do trabalho, sendo conhecidas atualmente como Economia Solidária (FRANÇA FILHO e LAVILLE, 2004).

Com o crescimento desse fenômeno no contexto organizacional, emergiu, também, o interesse da comunidade acadêmica em estudos nesse fenômeno. Diante disso, o objetivo deste trabalho é identificar e avaliar as publicações sobre o tema. 0 presente trabalho constitui-se em um estudo bibliométrico das publicações sobre Economia Solidária no Brasil no período entre 2001 a 2013.

O interesse pela realização desse estudo está na constituição de um panorama sobre os estudos acadêmicos realizados sobre Economia Solidária no Brasil, clarificando, entre outros aspectos, os principais pontos de debate, o delineamento das publicações e onde se concentram as publicações. A contribuição do trabalho está baseada na afirmação de Loiola e Bastos (2003), de que este tipo de levantamento é importante para incentivar a reflexão dos próprios pesquisadores sobre os desafios e limites que cercam a sua prática.

Este artigo está estruturado da seguinte forma: na primeira parte, apresentam-se conceitos sobre Economia Solidária. Depois, apresentam-se o método utilizado e procedimentos para coleta de dados e análise. Os resultados que configuram os estudos de Economia Solidária no Brasil são apresentados em seguida. Por fim, apresentam-se as considerações finais do trabalho com uma discussão, apontando algumas limitações e perspectivas futuras de pesquisas.

\section{ECONOMIA SOLIDÁRIA}

\section{Origens e conceitos}

O conceito de Economia Solidária na Europa, segundo Gaiger (2009), tem sua origem em um novo capítulo da história da Economia Social, cujas raízes mais distantes datam do século XIX. Ele explica que, naquela época, face às turbulências sociais provocadas pela Revolução Industrial, o associativismo surgiu como uma resposta de operários e camponeses que se caracterizava desde seus primórdios por formas de gestão autônomas e democráticas. Para Laville e Roustang (1999), o conceito de Economia Solidária baseia-se em uma ênfase sobre o desejo da Economia Social, em sua origem, de evitar o fosso entre o econômico, o social e o político, pois é na articulação dessas três dimensões que se situam os fundamentos essenciais das Economias Social e Solidária. Os termos, segundo esses autores, tentam dar conta da originalidade de numerosas iniciativas da sociedade civil, que não se encaixam na trilogia legalizada na França das cooperativas, mutualidades e associações. Entretanto, os autores alertam que o termo não é a expressão do que seria desejável fazer, e sim, visa muito mais problematizar práticas sociais implantadas localmente.

Para Gaiger (2009), a Economia Social se opôs às tendências de redução da economia ao princípio do mercado e à racionalidade da acumulação privada. Com tais premissas, desempenhou um papel considerável na construção de regimes de bem estar social. Mas o referido autor também explica que essa Economia Social começou a apresentar sinais de debilitamento, no limiar do século XX, pois o movimento operário perdeu aos poucos o seu caráter mobilizador, e devido ao fato de ela sofrer um processo de assimilação ao regime dual Estado-Mercado. À medida em que o Mercado e o Estado foram assumindo suas funções de geração de riqueza e de assistência social, a solidariedade do tipo associativo recuou para um papel subsidiário.

Depois de um longo período de mudanças sociais, políticas e econômicas, marcadas, por exemplo, pelo envelhecimento da população, o reconhecimento e expansão dos serviços de cuidados às pessoas, o aumento das desigualdades gerado pela sucessão de políticas neoliberais e pela globalização resultante, presenciou-se a nova geração da Economia Social (LAVILLE, 2004). A respeito dessa, Gaiger (2009) faz as seguintes ponderações:

"Suas ações concretas e suas bandeiras atuais reclamam o caráter universal irrevogável dos direitos dos cidadãos e a necessidade de um novo sistema de regulação da economia. Ela refuta a separação entre as esferas social e econômica e a omissão dos seus vínculos recíprocos no debate político em torno dos modelos de sociedade. Seu olhar crítico sobre o silêncio da Economia Social precedente 
a respeito dessas questões, sua insistência quanto à dimensão política das iniciativas que promove

e sua adesão aos movimentos altermundialistas conduziram vários dos seus defensores a designá-

-la de Economia Solidária, termo então predominante na América Latina" (GAIGER, 2009, p. 84).

Na América Latina, o surgimento do conceito da Economia Solidária está relacionada aos aspectos e elementos constituintes da Economia Popular. Esta, por sua vez, é criada pelos próprios trabalhadores que não possuíam os meios de produção diante das transformações que estão ocorrendo no processo de trabalho (LEBOUTTE, 2003). Para Cattini (2003), as circunstâncias enfrentadas pelos trabalhadores fizeram com que surgissem empreendimentos que constituem a Economia Popular, tais como mercados populares, grupos de produção comunitária, associações, cooperativas, entre outros. Esses empreendimentos eram caracterizados por serem iniciativas informais e individuais, e organizados por grupos pequenos e/ou familiares. Surgiram para o enfrentamento das dificuldades geradas pela questão social e constituem-se em soluções assistenciais e são conhecidos pela inserção em benefícios públicos ou privados (RAZETO, 1999, SINGER, 2002). Essa atividade de empreendimento social e econômico suscitada pelos trabalhadores em busca de melhores condições de trabalho e vida também é designada e difundida por muitos como Economia Solidária.

O conceito de Economia Solidária, na América Latina, refere-se essencialmente ao conjunto de iniciativas que, a partir da associação livre e democrática dos trabalhadores, visa ganho econômico e benefícios como qualidade de vida, reconhecimento e participação cidadã (GAIGER, 2009). Para Singer e Souza (2000) ela é referida como um marco das relações socioeconômicas comunitárias locais, regionais e em redes, que se expandem em diferentes espaços geográficos. Gaiger (2004) resume a Economia Solidária como uma atividade de projeção e busca de reconhecimento na esfera pública, de reivindicação e de institucionalização das classes mais necessitadas, pela qual ela se constitui como um movimento social atuante no cenário político da América Latina.

De forma geral, a Economia Solidária não é uma alternativa somente para os pobres e excluídos, mas proporciona avanços em diversos domínios e contextos, e envolve de maneira responsável amplos segmentos da sociedade. Essa nova economia se propõe a recuperar socialmente o que o progresso tecnológico proporcionou e excluiu em determinadas situações (CATTANI, 2003). No entendimento de Singer (2002, p. 10),

\begin{abstract}
"a Economia Solidária é outro modo de produção, cujos princípios básicos são a propriedade coletiva ou associada do capital e o direito à liberdade individual. A aplicação desses princípios une todos os que produzem numa única classe de trabalhadores que são possuidores de capital por igual em cada cooperativa ou sociedade econômica. O resultado natural é a solidariedade e a igualdade, cuja reprodução, no entanto, exige mecanismos estatais de redistribuição solidária da renda".
\end{abstract}

Assim, a economia solidária pode ser definida como "uma série de experiências organizacionais inscritas numa dinâmica atual em torno das chamadas novas formas de solidariedade" (FRANÇA FILHO, 2003, p. 13). Segundo o Fórum Brasileiro de Economia Solidária - FBES (2003), a Economia Solidária constitui o fundamento de uma globalização humanizadora, de um desenvolvimento sustentável, socialmente justo e voltado para a satisfação racional das necessidades de cada um e de todos os cidadãos da Terra, seguindo um caminho intergeracional de desenvolvimento sustentável na qualidade de sua vida. Já os apontamentos do Ministério do Trabalho e Emprego - MTE (2008) definem a Economia Solidária como um jeito diferente de produzir, vender, comprar e trocar o que é preciso para viver, sem explorar os outros, sem querer levar vantagem, sem destruir o ambiente, e cooperando, fortalecendo o grupo, cada um pensando no bem de todos e no próprio bem.

\title{
Tipos, características e princípios
}

Gaiger (2003) relata os empreendimentos econômicos solidários que se apresentam na forma de grupos de produção, associações, cooperativas e empresas de autogestão e combinam suas atividades econômicas com ações de cunho educativo e cultural, valorizando o sentido da comunidade e o compromisso com coletividade social em que se inserem. Esses empreendimentos apresentam uma diversidade de formas de economia alternativa, distintas da lógica mercantil capitalista. Dentre as formas nas quais a Economia Solidária se materializa, destacam-se as expostas no Quadro 1. 


\section{Quadro 1}

\section{Formas de Empreendimentos de Economia Solidária}

\begin{tabular}{|c|c|}
\hline Cooperativismo & $\begin{array}{l}\text { É a forma mais comum de Economia Solidária. "O cooperativismo é um } \\
\text { empreendimento, só que não é um empreendimento meramente econômico, } \\
\text { não é um empreendimento que visa lucro, é um empreendimento que visa } \\
\text { emancipação, que visa emancipar o indivíduo das atuais relações sociais" } \\
\text { (HADDAD, 2005, p. 27), }\end{array}$ \\
\hline Os Clubes de Trocas & $\begin{array}{l}\text { "É um espaço onde os associados trocam entre si produtos, serviços e saberes, } \\
\text { de uma forma solidária, promovendo a auto-ajuda, num sistema alternativo } \\
\text { à economia vigente, que respeita normas éticas e ecológicas". (CASTRO, } \\
\text { PASCALO, PRIMAVERA et al., 2003, p. 289). }\end{array}$ \\
\hline $\begin{array}{l}\text { Os LETS (Local Employment and Trading System } \\
\text { - Sistema Local de Emprego e Comércio). }\end{array}$ & $\begin{array}{l}\text { "É um sistema que congrega produtores em nível local, para intercambiarem } \\
\text { seus produtos mediante crédito mútuo" (SINGER, 2000, p. 132). }\end{array}$ \\
\hline Empresas autogestionárias & $\begin{array}{l}\text { O empreendimento mais simples de materializar a Economia Solidária. As } \\
\text { empresas autogestionárias, geralmente, nascem por iniciativa de trabalhadores } \\
\text { que se associam para formar uma empresa que será gerida e administrada } \\
\text { pelos próprios trabalhadores. }\end{array}$ \\
\hline Comércio Justo & $\begin{array}{l}\text { "É tido como uma forma alternativa ao comércio convencional, pois respeita } \\
\text { as necessidades das pessoas envolvidas, contribui para o desenvolvimento } \\
\text { sustentável, oferecendo melhores condições comerciais e visa proteger os } \\
\text { direitos dos trabalhadores" (JAFFEE, 2004). }\end{array}$ \\
\hline
\end{tabular}

Fonte: Adaptado de Martins, Crucial e Araújo (2006).

De maneira geral, pode-se utilizar os apontamentos de Razeto (1997) para caracterizar traços distintivos desses tipos de organizações apresentados no Quadro 1. Este autor explica que empreendimentos característicos da Economia Solidária apresentam como eixo orientador a solidariedade, a cooperação, a partilha dos rendimentos, de informações e conhecimentos entre seus integrantes, bem como a autoajuda. Singer (2000) argumenta que a Economia Solidária lança os alicerces de novas formas de organização da produção, e oportuniza a muitos a possibilidade de se reintegrar à produção por conta própria individual ou coletiva.

Segundo Mance (2001), existem 4 critérios básicos para inserção em redes e empreendimentos de Economia Solidária: (1) não haver nenhum tipo de exploração; (2) ser gerido democraticamente; (3) preservar o meio ambiente; e, por fim, (4) assegurar a autodeterminação dos fins e autogestão dos meios. Dessa forma, "a Economia Solidária brasileira não se resume, segundo nossa leitura, a algumas formas de cooperativismo. Ela absorve um certo número de iniciativas sob a forma associativa, assim como alguns casos de ONGs e fundações" (FRANÇA-FILHO e LAVILLE, 2004, p. 149).

No que se refere aos princípios da Economia Solidária, a FBES (2003) descreve, de maneira geral, os seguintes: (1) a valorização social do trabalho humano; (2) a satisfação plena das necessidades de todos como eixo da criatividade tecnológica e da atividade econômica; (3) o reconhecimento do lugar fundamental da mulher e do feminino em uma economia fundada na solidariedade; (4) a busca de uma relação de intercâmbio respeitoso com a natureza, e (5) os valores da 
cooperação e da solidariedade. Esses aspectos orientam as atividades sociais diversas e ações empreendedoras voltadas para a Economia Solidária.

A Economia Solidária, portanto, constitui-se em uma das formas de os sujeitos contestarem o sistema, seja por meio dos princípios nos quais os trabalhadores inseridos nesses empreendimentos estão respaldados, seja pela compreensão dos mesmos em relação ao modo com que ocorre a produção e comercialização existentes, em que predominam a individualidade, a competitividade e a consequente exclusão social (GOERCK e FRAGA, 2010). Ela compreende o conjunto de atividades econômicas de produção, distribuição, consumo, poupança e crédito, organizadas sob a forma de autogestão.

\section{PROCEDIMENTOS METODOLÓGICOS}

Referente ao tipo de pesquisa, esse estudo classifica-se como descritivo por revelar as características de determinado assunto por meio dos seus componentes, procurando avaliá-los (TRIVIÑOS, 1990; GIL, 2009). A abordagem predominante do artigo é quantitativa dada a característica dos dados e pela forma que estes foram utilizados e apresentados (a partir de gráficos e números). Para o desenvolvimento deste trabalho, foi utilizado o método de pesquisa bibliométrico, que permite realizar o mapeamento da produtividade científica de periódicos e representação da informação (BRÄSCHER e CAFÉ, 2008), permitindo observar a evolução da literatura sobre o assunto no decorrer dos anos (ARAUJO, FREIRA, AUTRAN et al., 2000).

Com o intuito de verificar e oferecer uma visão analítica sobre o tema em questão neste trabalho e tendo em vista o objetivo do trabalho, esse estudo bibliométrico foi realizado compreendendo o espaço temporal entre os anos de 2001 e 2013. Os artigos foram coletados na base de dados Scielo e Spell. Foram utilizadas essas bases de artigos por elas apresentarem uma representação eficiente da produção científica brasileira nos assuntos das ciências sociais. A pesquisa foi delineada tendo como palavra-chave o termo "economia solidária". Considerou-se que essa palavra-chave poderia estar contida nos seguintes campos de busca: título, resumo, assunto. Esses critérios e procedimentos de busca resultaram em 106 artigos no período definido. No entanto, verificou-se que alguns artigos estavam repetidos nas bases, e assim, foi realizada uma filtragem e eles foram contados apenas uma vez. Assim, no total, foram identificados um total de 93 artigos que foram tomados como unidades de análise deste estudo para demonstrar como foi o interesse acadêmico sobre o tema e como este evoluiu nos estudos brasileiros ao longo dos anos.

Para a consecução do objetivo proposto, foram analisados os seguintes aspectos tomados como objetivos específicos: (a) quantidade de artigos publicados no período; (b) quais os periódicos que se destacam na quantidade de publicações e o qualis desses periódicos; (c) quais os temas mais relacionados ao assunto; (d) quais autores mais contribuíram com artigos; (e) a quais universidades esses autores pertencem; (f) qual(is) o(s) grupo(s) de autores mais citados e que, assim, mais contribuíram para a geração da literatura em Economia Solidária; e (g) os indicadores das redes sociais de cooperação entre os autores.

Os dados da pesquisa foram reunidos e tabulados no programa Exce ${ }^{\circledR}$ e a partir daí foram elaborados gráficos para a análise e discussão dos dados. Para alcançar o objetivo de identificar quais os grupos de autores que mais contribuíram com o tema, foi utilizado o software Ucinet ${ }^{\circledR} 6$, que é um software para estudo de redes sociais e outros dados de proximidade, fornecendo dezenas de análises, como medidas de centralidade, por exemplo, e uma diversidade de gerenciamento de dados e ferramentas de transformação, desde a teoria dos grafos até a linguagem da álgebra matricial (SCIENCE PULS GROUP, 2009).

As redes de relacionamento que se formam pelas pesquisas conjuntas dos autores sobre determinado tema se constituem como uma alternativa à visão estática do papel do indivíduo ou grupo em um contexto e permitem identificar as relações e as influências entre os pesquisadores (GUIMARÃES e MELO, 2005). Para a construção dos grupos de relacionamento entre os autores, buscou-se verificar quais eram os autores centrais nessas redes de relacionamento a partir do número de publicações. Com isso, é possível verificar qual ator é mais importante dentro da rede e pesquisar qual o tema que determinada rede aborda em seus estudos. 


\section{ANÁLISE E DISCUSSÃO DOS RESULTADOS}

Nesta seção, apresentam-se e discutem-se os resultados encontrados a partir da pesquisa realizada, buscando alcançar o objetivo principal que norteia a realização deste trabalho. De forma a organizar a apresentação, esses resultados serão descritos seguindo os aspectos especificados no método do trabalho.

\section{(a) quantidade de artigos publicados no período:}

O primeiro desse aspecto a ser apresentado e explicado refere-se ao número de artigos publicados por ano nas duas bases. No Gráfico 1, exibem-se esses resultados.

Gráfico 1

Número de artigos publicados ao longo dos anos

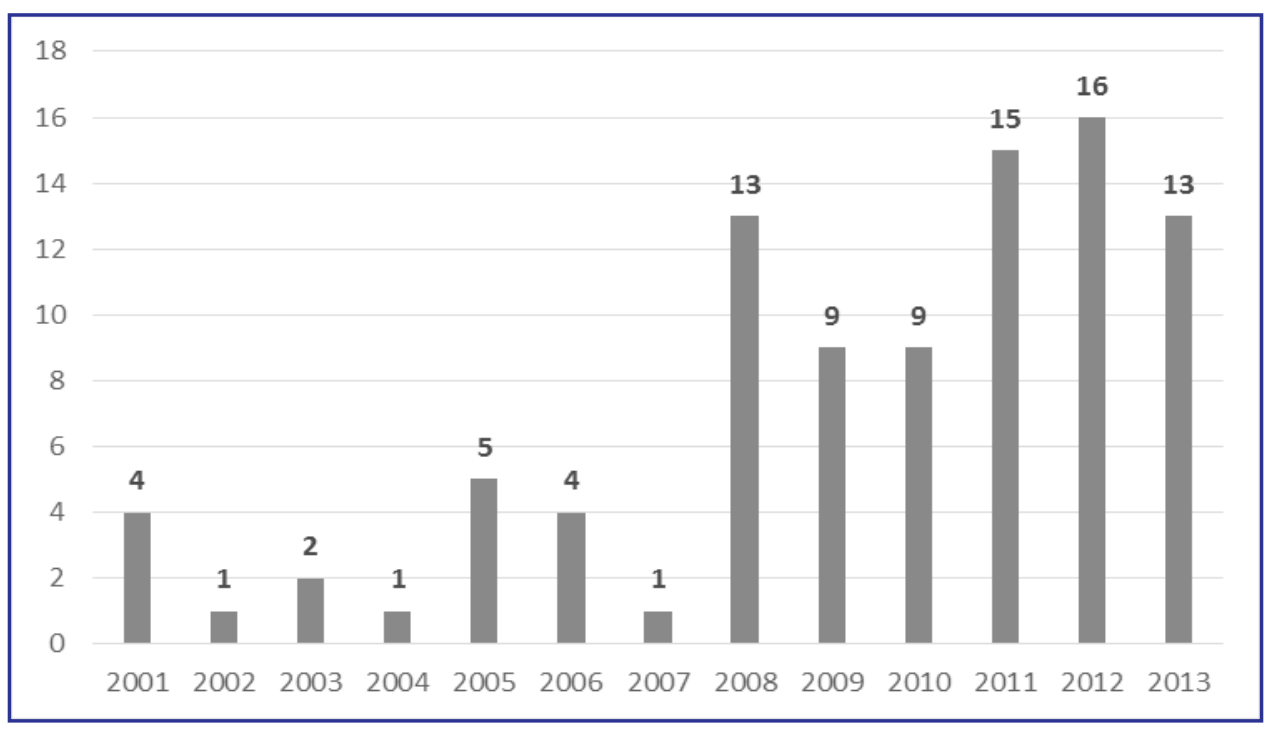

Fonte: Elaborado pelos autores.

Avaliando-se o Quadro 1, chama atenção e pode ser destacado o fato de as publicações não possuírem um crescimento linear ao longo dos anos avaliados. Pode-se verificar que os anos de 2008 (13 artigos), 2011 (15 artigos), 2012 (16 artigos) e 2013 (13 artigos) apresentam o maior número de artigos publicados. Esses resultados demonstram certa oscilação das publicações sobre o tema, mas mostram que há um interesse da comunidade acadêmica em formar um corpo teórico sólido sobre esse assunto, principalmente pela continuidade mais elevada das publicações a partir de 2008. A presença de publicações de forma consecutiva sobre Economia Solidária nesses últimos anos dá subsídios a este aspecto.

De forma a especificar a quantidade de artigos publicada ao longo dos anos nas duas bases em que a pesquisa foi realizada, elaborou-se a Tabela 1. Nesta tabela, mostram-se quantos artigos foram publicados na base Scielo e Spell, respectivamente, no período analisado. 
Tabela 1

Quantidade de artigos publicados nas bases Scielo e Spell no período

\begin{tabular}{|c|c|c|c|c|c|c|c|c|c|c|c|c|c|c|}
\hline BASE - ANO & 2001 & 02 & 03 & 04 & 05 & 06 & 07 & 08 & 09 & 10 & 11 & 12 & 2013 & TOTAL \\
\hline SCIELO & 3 & 1 & 0 & 0 & 0 & 3 & 0 & 10 & 5 & 4 & 7 & 8 & 8 & 49 \\
\hline SPELL & 1 & 0 & 2 & 1 & 5 & 1 & 1 & 3 & 4 & 5 & 8 & 8 & 5 & 44 \\
\hline
\end{tabular}

Fonte: Elaborado pelos autores.

Analisando-se a Tabela 1, pode-se verificar que na base Scielo foram publicados mais artigos que na base Spell. No entanto, um fato que também pode ser observado é que na base Spell houve maior linearidade nas publicações, visto que somente no ano de 2002 é que não foi publicado nenhum artigo sobre o tema em periódicos dessa base. Já a base Scielo apresenta mais anos com maior quantidade de artigos publicados em determinado ano, mas em outros, como em 2003, 2004, 2005 e 2007, nenhum artigo foi publicado em seus periódicos.

\section{(b) quais os periódicos que se destacam na quantidade de publicações e o qualis desses periódicos;}

Quanto às publicações em periódicos, de maneira específica, elaborou-se a Tabela 2, com o representativo das revistas que se destacam pela maior quantidade de artigos publicados no período analisado. De forma complementar, adicionou-se o qualis dessas revistas para se ter uma representação da qualidade desses artigos publicados.

Tabela 2

Publicações nos periódicos por ano

\begin{tabular}{|c|c|c|c|c|c|c|c|c|c|c|c|c|c|c|c|}
\hline REVISTA & 2001 & 2002 & 2003 & 2004 & 2005 & 2006 & 2007 & 2008 & 2009 & 2010 & 2011 & 2012 & 2013 & TOTAL & QUALIS \\
\hline Sociedade e Estado & 3 & 1 & 0 & 0 & 0 & 2 & 0 & 1 & 1 & 1 & 0 & 3 & 1 & 13 & B1 \\
\hline Revista Katálysis & 0 & 0 & 0 & 0 & 0 & 0 & 0 & 8 & 1 & 0 & 0 & 0 & 0 & 9 & N.C. \\
\hline $\begin{array}{l}\text { Organizações \& } \\
\text { Sociedade }\end{array}$ & 1 & 0 & 0 & 0 & 0 & 1 & 0 & 1 & 1 & 1 & 1 & 0 & 0 & 6 & $\mathrm{~A} 2$ \\
\hline Cadernos EBAPE.BR & 0 & 0 & 0 & 1 & 1 & 0 & 0 & 1 & 2 & 0 & 1 & 0 & 0 & 6 & B1 \\
\hline $\begin{array}{l}\text { Revista Eletrônica } \\
\text { Gestão e Serviços }\end{array}$ & 0 & 0 & 0 & 0 & 0 & 0 & 0 & 0 & 0 & 0 & 4 & 0 & 0 & 4 & B4 \\
\hline $\begin{array}{c}\text { Desenvolvimento em } \\
\text { Questão }\end{array}$ & 0 & 0 & 1 & 0 & 0 & 0 & 0 & 0 & 0 & 1 & 0 & 2 & 0 & 4 & B1 \\
\hline $\begin{array}{l}\text { Revista Eletrônica de } \\
\text { Ciência Administrativa }\end{array}$ & 0 & 0 & 0 & 0 & 0 & 0 & 1 & 0 & 0 & 0 & 1 & 0 & 1 & 3 & B2 \\
\hline Semestre Econômico & 0 & 0 & 0 & 0 & 0 & 0 & 0 & 0 & 2 & 0 & 1 & 0 & 0 & 3 & N.C. \\
\hline
\end{tabular}

Fonte: Elaborado pelos autores.

Nota: N.C. significa que a revista não possui classificação no qualis capes na área de administração.

Analisando-se a Tabela 2, pode-se perceber que a revista Sociedade e Estado da UNB-DF é a revista que apresenta a maior quantidade de artigos publicados sobre o tema no período (13 artigos). Já a segunda revista com mais artigos publicados é a revista Katálysis da Universidade Federal de Santa Catarina (UFSC), com 9 publicações. No entanto, deve-se destacar que 8 dessas publicações foram em 2008, quando foi lançada uma edição especial sobre o tema Economia Solidária e gestão, o 
que explica essa quantidade de publicações. Isso demonstra que havendo o incentivo e a oportunidade de publicar, o tema poderia ter um crescimento contínuo.

\section{(c) Quais os temas paralelos mais relacionados ao assunto Economia Solidária}

Com o intuito de proporcionar um panorama geral sobre o tema, elaborou-se uma tabela com as palavras-chave específicas que foram tratadas nos artigos, procurando identificar como o estudo é abordado ao longo dos anos analisados. Os resultados dessa análise estão demonstrados na Tabela 3.

Tabela 3

Temas mais abordados sobre Economia Solidária - ANPAD e SciELO

\begin{tabular}{|c|c|}
\hline PALAVRAS-CHAVE & ARTIGOS \\
\hline Gestão & 18 \\
\hline Empreendedorismo & 14 \\
\hline Trabalho & 14 \\
\hline Social/Socialismo & 11 \\
\hline Cooperação/Cooperativismo & 8 \\
\hline Organizações & 8 \\
\hline Práticas & 7 \\
\hline Desafios & 6 \\
\hline Desenvolvimento & 6 \\
\hline Experiências & 5 \\
\hline Inserção & 5 \\
\hline Políticas & 5 \\
\hline
\end{tabular}

Fonte: Elaborado pelos autores.

Ao analisar esses dados da Tabela 3, pode ser observado que as palavras mais utilizadas são gestão (18), empreendedorismo (14) e trabalho (14). Esses resultados podem ser justificados pelo fato de haver uma relação entre esses 3 termos. Segundo Gaiger (2008), a dimensão empreendedora é indissociável da dimensão solidária dos empreendimentos, onde os empreendimentos associativos funcionam e expandem seu quadro social principalmente com base em relações de cooperação. 0 trabalho realizado nesses empreendimentos e a gestão deles também exercem, assim, influência determinante no sucesso dessas ações empreendedoras. Tudo isso está inter-relacionado com o trabalho e autogestão, que se baseia nos princípios da Economia Solidária e na forma de empreender dessas organizações coletivas para ser uma forma de trabalho justo e democrático. Outra explicação para ligação desses três termos está no fato de que os empreendimentos econômicos solidários abarcam um amplo leque de agrupamentos, sob a forma de empresas autogeridas pelos trabalhadores, pequenas e médias associações ou cooperativas de produção, comercialização e dos mais variados serviços; projetos comunitários e cooperativas agropecuárias (GAIGER, 2008).

\section{(d) quais os autores que mais contribuíram com artigos; (e) a quais as universidades esses autores pertencem;}

Para verificar os autores que mais trabalharam com a perspectiva da Economia Solidária, estruturou-se a Tabela 4, onde é possível analisar tal aspecto, bem como a universidade a qual eles pertencem. 
Tabela 4

Autores que publicaram sobre Economia Solidária

\begin{tabular}{|c|c|c|}
\hline AUTOR & UNIVERSIDADE & N. de ARTIGOS \\
\hline Genauto Carvalho de França Filho & Universidade Federal da Bahia & 7 \\
\hline Luiz Inácio Germany Gaiger & Universidade do Vale do Rio dos Sinos & 3 \\
\hline Luis Miguel Luzio dos Santos & Universidade Estadual de Londrina & 3 \\
\hline Deise Luiza da Silva Ferraz & Universidade Federal de Minas Gerais & 3 \\
\hline Marco Aurélio Bernardes & Universidade Federal de São João del-Rei & 3 \\
\hline Eduardo Vivian da Cunha & Universidade Federal do Cariri & 3 \\
\hline Washington José de Souza & Universidade Federal do Rio Grande do Norte & 4 \\
\hline
\end{tabular}

Fonte: Elaborado pelos autores.

Ao analisar a Tabela 4, pode-se ver que o autor que mais teve publicações no período analisado sobre o tema Economia Solidária é o professor Genauto Carvalho, com 7 trabalhos, da Universidade Federal da Bahia. Em seguida, destaca-se o professor Luiz Gaiger da Universidade do Vale do Rio dos Sinos com 4 publicações, e os outros autores constantes na Tabela 4 com 3 publicações cada um. Ressalta-se que foi decidido expor autores com no mínimo 3 publicações na Tabela 4, pois eles são os únicos que apresentam 3 ou mais publicações no assunto deste trabalho no período analisado. Os demais autores obtidos na pesquisa apresentavam apenas 1 ou 2 publicações.

\section{(f) Quais os grupos de autores que se destacam sobre Economia Solidária; e (g) os indicadores das redes sociais de cooperação entre os autores.}

De maneira a especificar as relações entre os autores no tema economia solidária, esquematizou-se a Figura 1. Essa figura proporciona um panorama geral dos autores que trabalham com o tema. Nas análises subsequentes, especificam-se essas relações bem como qual a relação dos principais grupos de autores com os temas que mais se destacam nas suas respectivas publicações, buscando identificar se há um determinado foco de estudo em certo grupo de autores.

Ao analisar o Gráfico 1, torna-se importante dizer que a análise incidiu sempre sobre uma estrutura parcial de rede, definida com subgrupos formados na própria rede estudada de autores. Dessa maneira, não se buscou representar todas as relações possíveis, mas sim as realmente existentes entre cada autor envolvido, examinando o diagrama (ou grafo) de rede (MONTEIRO, 2002). Essa análise remete à medida de centralidade de determinado autor. Segundo Hanneman e Riddle (2005), a verificação da centralidade de grau da rede permite analisar a relevância dos atores nesse ambiente, assim como a importância da formação de laços. Quanto maior o número de laços constituídos por um ator, maior a possibilidade de influência deste sobre os outros componentes da rede, pois maior quantidade de conexões pode corresponder a maior acesso a informações e recursos para o desenvolvimento de suas atividades. Um maior degree também pode corresponder à possibilidade de tal ator sofrer mais pressões e influências do contexto em que está inserido, considerando-se que este fica mais exposto às interações ocorridas em tal ambiente (ULRICH, OLIVEIRA e SCHEFFER, 2012). 


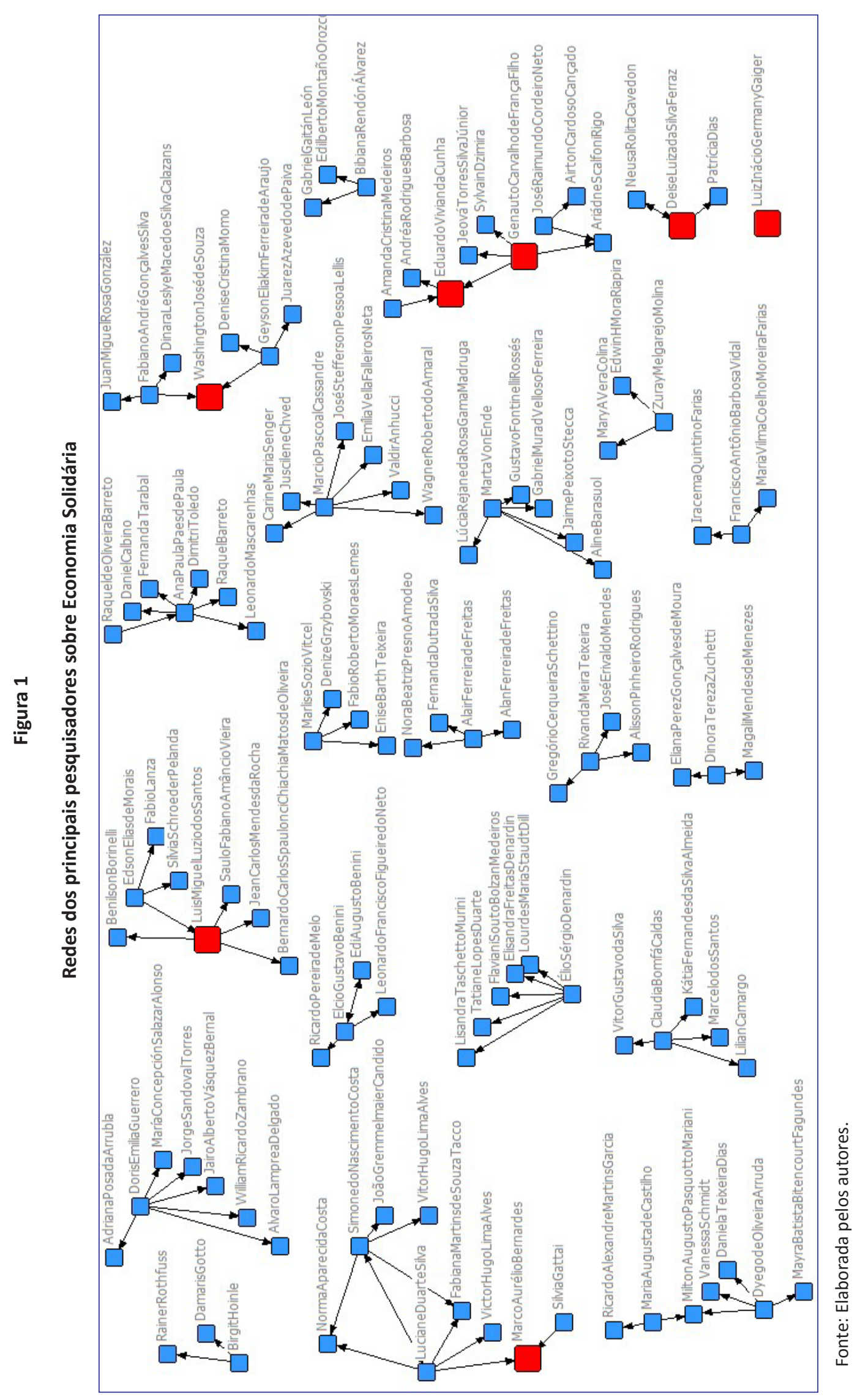


Pode-se identificar na Figura 1 que dentre os 7 principais autores sobre o tema, 4 grupos principais são formados com os autores que mais publicaram sobre o tema, e que, para fins de análise do grupo, foram tomados como atores centrais da rede social. 0 primeiro grupo a ser destacado é o do professor Genauto Carvalho de França Filho, que, conforme destacado anteriormente, possui 7 artigos publicados sobre o tema e tem experiências com as temáticas Economia Solidária, associativismo, terceiro setor, economia popular e novas formas de solidariedade. 0 seu grupo de relações possui como integrante outro professor que foi destacado na Tabela 4, o autor Eduardo Vivian da Cunha. Este, por sua vez, trabalha principalmente com os seguintes temas, além de Economia Solidária: incubação, redes, desenvolvimento local e sustentabilidade. Em comum, esses dois autores possuem, aparentemente, o interesse no associativismo e nas formas de solidariedade para o desenvolvimento local.

Outro grupo a ser destacado é o do professor Luis Miguel Luzio dos Santos pela quantidade de relações diretas que ele conduz com outros autores. Esse autor atua prioritariamente nas áreas de socioeconomia, democracia econômica, associativismo, políticas públicas e solidariedade, mas possui como projeto orientador de suas pesquisas os fatores determinantes na consolidação de empreendimentos de Economia Solidária. Isso, aliado com suas relações e parcerias com outros autores, ao que parece, justifica suas publicações.

O grupo liderado por Washington José de Souza apresenta poucas relações diretas com ele (apenas 2), apesar de 6 autores estarem envolvidos na sua rede, seja de forma direta ou indireta. Os seus interesses de pesquisa estão focados nos seguintes temas: Economia Solidária, trabalho e qualidade de vida, protagonismo juvenil e empreendedorismo social, gestão de organizações não-governamentais, extensão inovadora, replicação e avaliação de projetos e ações públicas e sociais.

Da mesma forma que o grupo anterior, o grupo de autores que tem como destaque o professor Marco Aurélio Bernardes apresenta poucas relações diretas com ele. Esse professor possui diversas pesquisas com outros autores internacionais, uma vez que obteve seu doutorado em uma universidade estrangeira. Mas, no que se refere ao tema Economia Solidária, ele possui seu foco de interesse com outros 8 autores, abrangendo empreendedorismo social, solidariedade, atividades sociais e associativismo.

Por fim, dentre os autores que se destacam pela quantidade de publicações, ressalta-se o autor Luiz Inácio Germany Gaiger, que obteve suas publicações de forma isolada. Nesse seu foco em Economia Solidária, ele engloba paralelamente o cooperativismo, as práticas sociais e a solidariedade. Além desse autor, destaca-se também a professora Deise Luiza da Silva Ferraz, que possui suas publicações sobre Economia Solidária com apenas 2 outros autores. Ela aborda a exclusão e a inclusão social, as práticas autogestionárias, a economia popular e a solidariedade. 


\section{CONCLUSÃO}

Este artigo foi elaborado tendo como objetivo identificar e avaliar as publicações sobre o tema Economia Solidária. A análise das publicações no período compreendido entre 2001 a 2013 possibilitou estabelecer um panorama das pesquisas realizadas no Brasil nos últimos anos, permitindo, com isso, atingir o objetivo proposto no trabalho.

A primeira consideração a ser realizada e destacada é que existe uma concentração dos estudos de Economia Solidária em diferentes grupos e redes de pesquisa. A contribuição do presente estudo foi identificar alguns desses grupos e/ou redes e onde estão os potenciais autores a serem acompanhados ao longo dos próximos anos para uma consolidação do tema. Ressalta-se que, apesar de serem destacados na análise dos grupos e rede de relações os autores os que mais tinham publicações sobre o tema no período analisado, outros grupos e autores com menores quantidades de artigos também podem ser identificados, vide Figura 1. Aparentemente, há uma necessidade de maior aproximação entre os grupos de estudos do tema e, nesse sentido, espera-se que o presente estudo possa contribuir demonstrando o caminho até o momento realizado pelos pesquisadores que buscaram discutir sobre essa temática.

O segundo aspecto a ser destacado refere-se aos periódicos que, apesar de a análise poder ter sido influenciada por edições especiais sobre o tema, verifica-se uma carência de periódicos com foco e escopo relacionado diretamente ao tema aqui apresentado. No entanto, há que se ressaltar que a pesquisa no campo da Economia Solidária, no Brasil, encontra-se em estágio inicial e, por isso, inviabiliza qualquer tipo de conclusão ou considerações definitivas ou até mesmo amparadas por vasto material de apoio.

Sugere-se, para futuros estudos, a possibilidade de um estudo comparativo com trabalhos publicados em periódicos internacionais e, também, uma comparação entre os trabalhos apresentados em eventos nacionais e internacionais, buscando uma compreensão mais abrangente sobre o tema. Além disso, sugere-se um estudo comparativo por países para verificar o quanto essa temática evolui em cada país estudado, com o intuito de se ter uma referência sobre os países de interesse sobre o tema. É importante, também, uma ampliação da base de dados dessa pesquisa, mapeando a produção em periódicos de outras áreas próximas ao tema, como economia, ciências sociais e serviço social. Também pode ser fonte valorosa de investigação o mapeamento de dissertações e teses dos programas de Mestrado e Doutorado em Administração e áreas afins. 


\section{REFERÊNCIAS BIBLIOGRÁFICAS}

ARAUJO, W. T. et al. Meta-análise das dissertações do curso de mestrado ciência da informação UFPB: 1990-1999. Revista Informação e Sociedade: estudos, João Pessoa, v. 10, n. 1, p. 1-11, 2000.

BARRETO, R. O.; LOPES, F. T.; PAULA, A. P. P. A Economia Solidária na inclusão social de usuários de álcool e outras drogas: Reflexões a partir da análise de experiências em Minas Gerais e São Paulo, Anais... XXXV Encontro da ANPAD, Rio de Janeiro, 2011.

BARRETO, R. O.; PAULA, A. P. P. Os dilemas da economia solidária: um estudo acerca da dificuldade de inserção dos indivíduos na lógica cooperativista. Cad. EBAPE.BR, Rio de Janeiro, v. 7, n. 2, p. 219-213, 2009.

BRÄSCHER, M.; CAFÉ, L. Organização da Informação ou Organização do Conhecimento? In: Encontro Nacional de Pesquisa em Ciência da Informação, 2008, São Paulo, Anais... São Paulo: ANCIB, 2008.

CASTRO, C. H. et al. O clube de trocas de São Paulo. In: SINGER, P.; SOUZA, A. R. de (Org.). Economia Solidária no Brasil: a autogestão como proposta ao desemprego. 2. ed. São Paulo: Contexto, 2003. 289-302 p.

CATTANI, D. A. (Org.). A Outra Economia. Porto alegre: Veraz, 2003. FBES - FÓRUM BRASILEIRO DE ECONOMIA SOLIDÁRIA. Carta de Princípios da Economia Solidária. III Plenária Nacional da Economia Solidária, 2003. Disponível em: http://www.fbes.org.br/index. php?option $=$ com_content\&task $=v i e w \& i d=63 \&$ Itemid $=60$. Acesso em 14 de julho de 2014.

FRANÇA FILHO, G. C.; LAVILLE, J. Economia Solidária: uma abordagem internacional. Porto Alegre: Editora da UFRGS, 2004.

GAIGER, L. I. Empreendimentos econômicos solidários. In: CATTANI, A. (Org.). A outra economia. Porto Alegre: Veraz, 2003. 135-143 p.

GAIGER, L. I. A economia solidária e o projeto de outra mundialização. DADOS - Revista de Ciências Sociais, v. 47, n. 4, p.799-834, 2004

GAIGER, L. I. Antecedentes e expressões atuais da economia solidária. Revista Crítica de Ciências Sociais, v. 84, p. 81-99, março 2009.

GAIGER, L. I. A dimensão empreendedora da economia solidária: notas para um debate necessário. Outra economia, v. 2, n. 3, p. 58-72, 2011.

GIL, A. C. Métodos e técnicas de pesquisa social. 4. ed. São Paulo: Atlas, 2009.

GOERCK, C.; FRAGA, C. K. Economia Popular Solidária no Brasil: um espaço de resistência às manifestações de desigualdade da questão social. Vivências: Revista Eletrônica de Extensão da URI, v. 6, n. 9, p. 103-111, 2010.

GUIMARÃES, F. J. Z.; MELO, E. de S. Diagnóstico utilizando análise de redes sociais. $60 \mathrm{f}$. Monografia (Especialização Engenharia de Produção). Universidade Federal do Rio de Janeiro, Rio de Janeiro, 2005.
HADDAD, F. Hay que ser solidário pero sin perder la combatividad jamás. In: MELLO, S. L. de (Org.). Economia Solidária e autogestão: encontros internacionais. São Paulo: NESOL-USP, ITCP-USP, PW, 2005. 22-28 p.

JAFFEE, D. Brining the moral charge home: Fair trade whitin the North and whitin the South. Rural Sociology, v. 69, n. 2, p. 169-196, 2004

LAVILLE, J-L. (Org.). Economía social y solidaria. Una visión europea. Buenos Aires: Altamira, 2004.

LAVILLE, J-L.; ROUSTANG, G. L'enjeu d'un partenariat entre État et société civile. In: DEFOURNY e outros. Economie social au Nord et au Sud. Bruxelles: Deboeck, 1999. 217-238 p.

LEBOUTTE, P. Economia Popular Solidária e políticas públicas: a experiência pioneira do Rio Grande do Sul. Rio de Janeiro: ITCP/ COPPE, 2003.

LOIOLA, E.; BASTOS, A. V. B. A produção acadêmica sobre aprendizagem organizacional no Brasil. Revista de Administração Contemporânea, v. 7, n. 3, p. 181-201, 2003.

MANCE, E. A Revolução das Redes: a colaboração solidária como alternativa pós-capitalista à globalização atual. Petrópolis, RJ: Vozes, 2001.

MARTINS, C. H.; CRUCIAL, C. V.; ARAÚJO, E. J. C. Economia e Comunhão e Economia Solidária: uma Distinção de Conceitos. Anais... XXVII EnANPAD, 2006.

MTE - MINISTÉRIO DO TRABALHO E EMPREGO. O que é Economia Solidária? Brasília, 2008. Disponível em: <http://portal.mte.gov.br/ecosolidaria/o-que-e-economia-solidaria.htm>. Acesso em 11 de julho de 2014

OLIVEIRA, A. L.; REZENDE, D. C.; CARVALHO, C. C. Redes interorganizacionais horizontais vistas como sistemas adaptativos complexos coevolutivos: o caso de uma rede de supermercados. Revista de Administração Contemporânea (RAC), v. 15, n. 1, p. 67-83, 2011.

RAZETO, L. O papel central do trabalho e a economia de solidariedade. Proposta, v. 75, p. 91-99, 1997.

SCIENCE PLUS GROUP. Ucinet software descriptions. Disponível em: <http://www.scienceplus.nl/ucinet>. Acesso em 7 de junho de 2014.

SINGER, P. Globalização e desemprego: diagnóstico e alternativas. São Paulo: Contexto, 2000.

SINGER, P. Introdução à Economia Solidária. São Paulo: Editora Fundação Perseu Abramo, 2002.

SINGER, P.; SOUZA, A. R. (Org.). A Economia Solidária no Brasil: a autogestão como resposta ao desemprego. São Paulo: Contexto, 2000.

TRIVIÑOS, A. N. S. Introdução à pesquisa em ciências sociais: a pesquisa qualitativa em educação. São Paulo: Atlantas, 1990.

ULRICH, D. R.; OLIVEIRA, J. S.; SCHEFFER, A. B. B. Formação de Redes Sociais de Coautoria na Área de Gestão de Pessoas: Uma Análise Bibliométrica em Periódicos Brasileiros no Triênio de 2007 a 2009. REGE, v. 19, n. 4, p. 553-570, 2012 
Juliano Nunes Alves

Doutorando em Administração na Universidade Federal de Santa Maria/UFSM; Professor da Universidade de Cruz Alta. E-mail: admjuliano@yahoo.com.br

Viviane Flaviano

Mestre em Administração na Universidade Federal de Santa Maria/UFSM. E-mail: vivianeflaviano@gmail.com

Leander Luiz Klein

Doutorando em Administração na Universidade Federal de Santa Maria/UFSM. E-mail: kleande88@gmail.com

Mauri Leodir Löbler

Doutor em Administração pela Universidade Federal do Rio Grande do Sul/UFRGS; Professor adjunto da Universidade Federal de Santa Maria. E-mail:mlobler@gmail.com

Breno Augusto Diniz Pereira

Doutor em Administração pela Universidade Federal do Rio Grande do Sul/UFRGS; Professor adjunto da Universidade Federal de Santa Maria. E-mail: brenodpereira@gmail.com

Cad. EBAPE.BR, v. 14, nº 2, Artigo 1, Rio de Janeiro, Abr./Jun. 2016. 